\title{
Synanthropy of Wild Mammals as a Determinant of Emerging Infectious Diseases in the Asian-Australasian Region
}

\author{
Ro McFarlane, ${ }^{1}$ Adrian Sleigh, ${ }^{1}$ and Tony McMichael ${ }^{1}$ \\ National Centre for Epidemiology and Population Health, ANU College of Medicine, Biology and Environment, Australian National University, \\ Canberra, Australia; romcfarlane@gmail.com; romcfarlane@gmail.com
}

\begin{abstract}
Humans create ecologically simplified landscapes that favour some wildlife species, but not others. Here, we explore the possibility that those species that tolerate or do well in human-modified environments, or 'synanthropic' species, are predominantly the hosts of zoonotic emerging and re-emerging infectious diseases (EIDs). We do this using global wildlife conservation data and wildlife host information extracted from systematically reviewed emerging infectious disease literature. The evidence for this relationship is examined with special emphasis on the Australasian, South East Asian and East Asian regions. We find that synanthropic wildlife hosts are approximately 15 times more likely than other wildlife in this region to be the source of emerging infectious diseases, and this association is essentially independent of the taxonomy of the species. A significant positive association with EIDs is also evident for those wildlife species of low conservation risk. Since the increase and spread of native and introduced species able to adapt to human-induced landscape change is at the expense of those species most vulnerable to habitat loss, our findings suggest a mechanism linking land conversion, global decline in biodiversity and a rise in EIDs of wildlife origin.
\end{abstract}

Keywords: emerging infectious diseases, zoonotic, synanthropy, biodiversity, land use, wildlife

\section{INTRODUCTION}

Some wildlife species survive or prosper in the environments modified by humans. Here, we test the hypothesis that wildlife that are synanthropic (i.e. ecologically associated with humans) predominate as hosts of zoonotic emerging and re-emerging infectious diseases (EIDs). EIDs are diseases that are either novel, or have increased their distribution or pathogenicity in the last 30 years, and are of

Published online: April 24, 2012

Correspondence to: Ro McFarlane, e-mail: romcfarlane@gmail.com global concern (IOM 2003; WHO et al. 2004). Zoonotic infections predominate among human EIDs, especially infections from wildlife (Jones et al. 2008; Taylor et al. 2001). The rise in EIDs of wildlife origin may be due to an increase in human population, movement, and encroachment on natural environments, as well as anthropogenic landscape modification, globalisation of trade (including trade of wildlife) and changing climate (e.g. Childs et al. 2007; Morse 1995).

The link between wildlife and EIDs is largely descriptive or conceptual (e.g. Daszak et al. 2000; Dobson et al. 2006; Epstein 2002; Froment 2009; Kruse et al. 2004; Pongsiri et al. 2009; Reperant 2010). Associations between zoonotic EIDs and regions of high biodiversity have been 
suggested (Jones et al. 2008) but biodiversity has also been shown to be protective (Ostfeld and Keesing 2000; Keesing et al. 2010). Wildlife trade and consumption of bush meat provide opportunities for pathogen transmission and this is considered a potentially important transmission mechanism (Chomel et al. 2007; Engel et al. 2002; Schillaci et al. 2005; Swift et al. 2007; Webster 2004; Wolfe et al. 2005). Global analysis of natural hosts of established zoonotic diseases suggests that species that historically had the most frequent and closest exposure with humans predominate, i.e. domesticated animals and synanthropic rodents (Cleaveland et al. 2001; Taylor et al. 2001; Woolhouse 2002; Woolhouse and Gaunt 2007).

This study investigates the occurrence of EIDs since the term 'emerging infection' first appeared in life science literature databases in 1973. We focus on the link between wildlife and EIDs, especially wild mammals, analysing the role of synanthropy, here measured as recorded use of human-modified environments (HME) (IUCN 2010). We restrict the study to South East Asia, East Asia and Australasia, regions with a high incidence of zoonotic EIDs from wildlife in recent decades. These are also regions of extensive, ongoing natural habitat and biodiversity decline. We tested the hypothesis that wildlife species that tolerate human activity are more likely to exchange pathogens with us, and survive, even in the face of ongoing biodiversity loss.

\section{Methods}

The study was conducted in three stages. The first stage was a systematic review of EID reports in literature covering the period 1973-2009 inclusive, using databases Scopus, CAB (Commonwealth Agricultural Bureaux) Abstracts and Web of Science. Papers were identified by key phrases'emerging infectious disease(s)', 'emerging communicable disease(s)' - and by region and country. The 23 countries included were from South East Asia (Indonesia, Timor Leste, Malaysia, Singapore, Thailand, Vietnam, Cambodia, Laos, Myanmar, Philippines, Brunei), East Asia (China, Taiwan, Hong Kong, Japan, Korea) and Australasia (Australia, New Zealand, Papua New Guinea, Solomon Islands, Fiji, New Caledonia, Vanuatu). The review produced a large number of disease-specific or review papers on EIDs of humans in Australasia (192), South East Asia (257) and East Asia (491). There were 104 emerging and re-emerging diseases identified.
The second stage involved description and summary of the identified EID reports, noting the occurrence of zoonoses and categorising them by host groups. The proportion of zoonotic emerging and re-emerging diseases and their sources were examined. Zoonotic diseases $(n=70)$ accounted for $67 \%$ of the total and $63 \%$ of these are zoonoses of wildlife origin $(n=44)$. Of these, 41 diseases were from wild mammals (see Fig. 1).

We restricted our third stage, the analysis of synanthropy, to mammals as they were identified as the primary host of $90 \%$ of total zoonotic diseases identified in the literature (see Fig. 2). We examined the link between zoonotic wild mammal hosts to synanthropy when compared to non-zoonotic wild mammals in the same subgroup. The International Union for the Conservation of Nature (IUCN) Red List database was consulted to assemble a complete list of all possible mammals for the region specified above, noting the recorded use of artificial, HME. Attention was also taken of the IUCN conservation assessment for each mammal, allowing for final consideration of the empirical evidence on the link between zoonotic hosts, synanthropy and conservation status. We also examine whether synanthropy and hunting represent alternate or overlapping potential risks for transmission from these hosts.

Abstracts from the literature review were reviewed to exclude papers where the disease in question was not infectious or had not emerged or re-emerged in the study region since 1970 (Morse 1995). Papers referring to zoonotic diseases were read in detail. Diseases were accepted as zoonotic where reservoir hosts were vertebrate animals and transmission pathways were established in the primary or cited literature. Information from the literature was organised in a database with disease, the unique identifier. The database included primary (definitive), intermediate and secondary host species, in addition to reservoir and amplification hosts. We included non-primary hosts in our database when identified as the source of zoonotic infection.

Host animals were identified at the levels of class, order and species. A total of 14 taxonomic orders encompass the mammalian fauna of the study region. However, the six most common were Artiodactyls (hoofed animals such as buffalo, goats, pigs), Carnivores (cats, dogs and their wild relatives), Chiroptera (bats), Eulipotyphla (small insectivorous mammals such as shrews), Primates (here used for non-human primates) and Rodents (including voles, gerbils, marmots, etc.). Species names were corrected and 


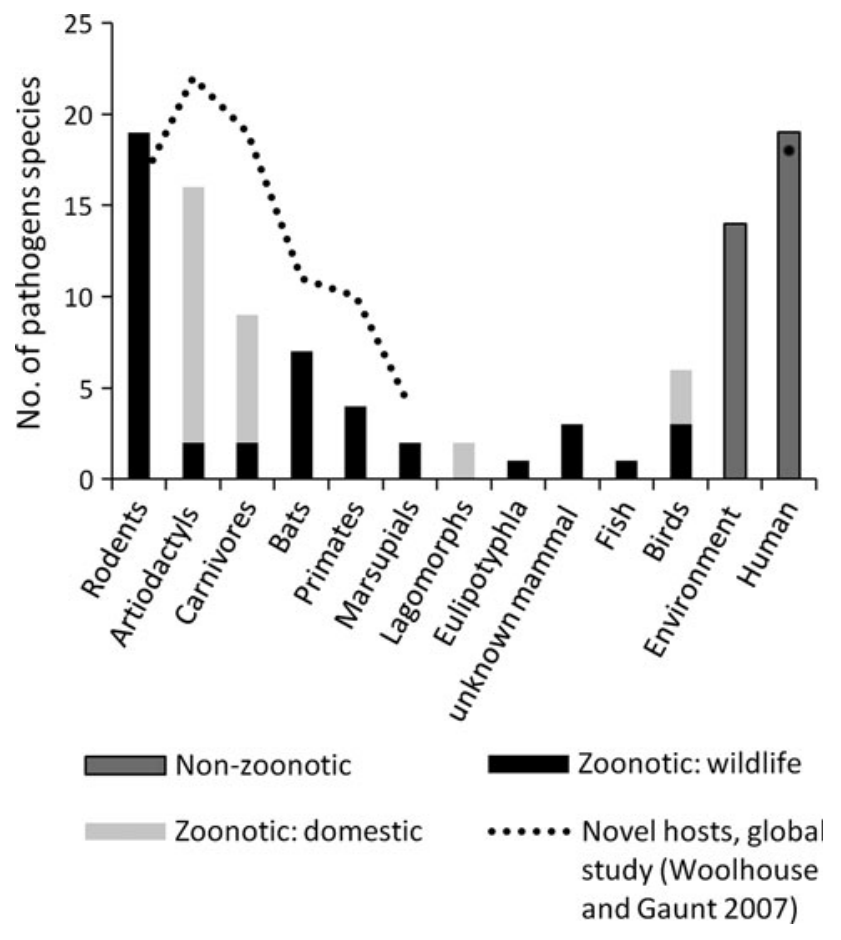

Figure 1. Emerging and re-emerging infectious diseases of humans 1973-2009 ( $n=104)$ in Australasia, South East Asia and East Asia by origin of pathogen. Data derived from a systematic review of literature 1973-2009 based on keywords emerging infectious disease(s) emerging communicable disease(s) and by region and country using databases Scopus, CAB and Web of Science (see text for details). Note that the figure excludes emerging infections which are new therapeutic-resistant strains of known organisms.

grouped using the International Code of Zoological Nomenclature. Scientific names are not used in the text except where a species does not appear in Table 2.

Domestic animals were not included in the analysis of wild mammal hosts and synanthropy since the process of domestication of animals deliberately selects for a positive association with HME. These were identified within the source literature. Wild (feral) alternative domestic hosts of the seven EIDs from carnivores and artiodactyls were excluded (i.e. only hosts of sylvatic cycles are retained in the analysis).

The final analysis of relationships between wild mammal hosts of EIDs, synanthropy and conservation status required identification of hosts to species level. This enabled extraction of species-specific characteristics from the IUCN Red List of Threatened Species Categories and Criteria Version 3.1 (www.iucnredlist.org). The multiple potential mammalian hosts of emerging Australian arboviruses were excluded as the specific species responsible

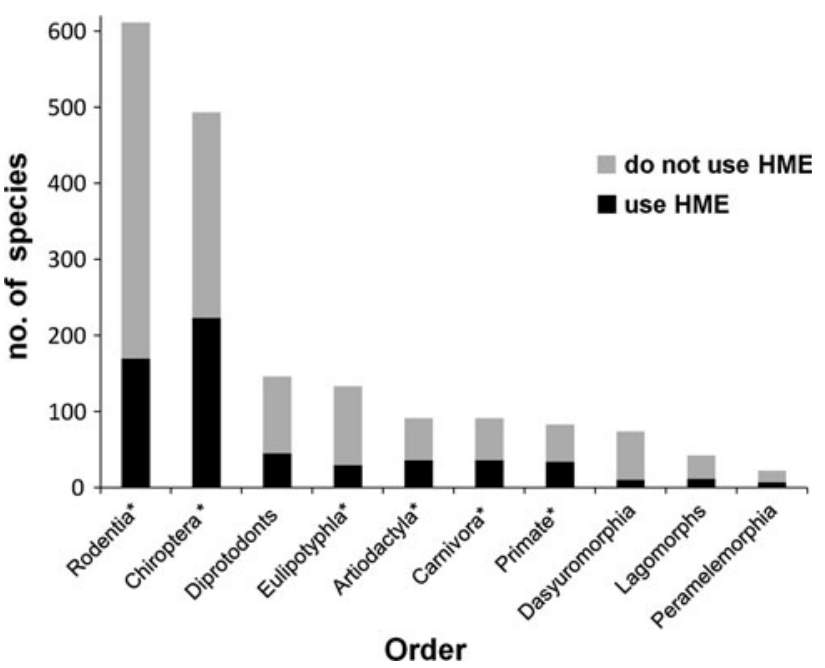

Figure 2. Wild mammals of Australasia, South East Asia and South Asia $(n=1823)$ by taxonomic order and human-modified environment $(H M E)$ use (IUCN 2010). Orders with $<10$ species $(n=6)$ not shown, orders containing wild mammal hosts of emerging infectious diseases are marked with asterisk $\left.{ }^{\star}{ }^{\star}\right)$.

for driving emergence and re-emergence are unknown and therefore, cannot be included in this analysis. Marsupials (in taxonomic orders Diprotodonts, Dasyuromorphia and Peramelemorphia) are believed to be the primary hosts of these diseases (Harley et al. 2001; Johansen et al. 2005).

Zoonotic hosts (and the balance of the total terrestrial native and introduced wild mammal fauna of the study region) were classified on the following criteria: taxonomic order, habitat use (including artificial (human-modified) habitats), conservation assessment, population trend and the conservation threat from hunting and trapping for intentional use or persecution/control (as an indication of potential pathogen exposure through this mode). These data are reported for the entire geographical distribution (range) of each species. The IUCN conservation assessments are based on criteria including population trend, size, structure and geographic distribution change to assess risk of population decline and extinction. See IUCN Red List (www.iucn.redlist.org) for details.

Chi-squared analysis was used to indicate if the observed relationship between the distribution of wild mammal species within taxonomic orders and their EID host status was likely to be due to chance. Then, for taxonomic order, HME use, conservation status and for threat from hunting, the relative odds of having these variables for EID versus non-EID hosts were calculated, showing the direction and strength of the host-factor association as an odds ratio (OR) and $95 \%$ confidence interval. Potential 
confounding of the association between EID host status and human-modified habitat use was examined by stratifying separately by taxonomic order, and conservation status. This also allowed assessment of effect modification.

For stratified analyses, summary ORs and $95 \%$ confidence intervals were calculated using the Mantel-Haenszel $(\mathrm{MH})$ procedure for weighting and averaging stratumspecific ORs. The stratum-specific ORs for taxonomic status were compared for heterogeneity to detect any modification of the host-factor relationships, and to justify the use of the $\mathrm{MH}$ procedure. Epidemiological software Epi Info 3.5.1(CDC 2008), EpiTools (Sergeant 2009) and statistical software Graph Pad (Motulsky 2002) were used in analyses. The method of empirically weighted least squares was used to test for heterogeneity between the odds ratios in stratified analyses (Cox and Snell 1989).

\section{Results}

Overall 44 zoonotic EIDs of wild mammal origin were identified from the systematic literature review and 41 host species were identified from the 1,823 species of wild mammals recorded from the study region. The primary analysis of this study finds that wild mammal hosts of EIDs are 15 times more likely to use HME than other wild mammals in the study region $(\mathrm{OR}=15.02 ; 95 \%$ CI 5.87, 38.41).

We find that the distribution of wild mammal hosts of EIDs across taxonomic orders is marginally significantly different from the distribution of all wild mammal species $(n=1,823)$ in the study region $\left(X_{5}^{2}=11.1, P=0.049\right)$. These include rodents $(n=19)$, bats $(n=14)$, primates $(n=3)$, carnivores $(n=3)$ and eulipotyphla $(n=2)$. Note the exclusion of domestic and feral artiodactyls and marsupials discussed earlier.

For the five EID host-containing taxonomic orders identified by the study (rodents, bats, primates, carnivores and eulipotyphla), the effect of synanthropy is independent of taxonomic order. Stratum-specific ORs for taxonomic order of hosts for the effect of synanthropy were not significantly different from the crude OR when weighted and averaged $\left(\mathrm{OR}_{\mathrm{MH}}=14.49 ; 95 \% \mathrm{CI} 5.71,45.74\right)$. The test for heterogeneity finds no significant difference between strata and hence the assumptions of the $\mathrm{MH}$ procedure are found to be valid. See Table 1 for stratum-specific results.

When the relationship between EID host and HME is stratified by conservation status (Least Concern vs. higher risk conservation categories) the crude $\mathrm{OR}$ is 15.2 but reduces in magnitude when weighted and averaged $\left(\mathrm{OR}_{\mathrm{MH}}=10.26 ; 95 \% \mathrm{CI} 4.15,33.05\right)$. Table 1 shows that the EIDs with higher risk conservation status $(n=4)$, are strongly associated with HME. Further, wild mammal EID hosts are eight times more likely to be classified as being within the Least Concern conservation assessment category $(\mathrm{OR}=8.56 ; 95 \% \mathrm{CI} 3.04,24.08)$ when this variable is examined separately.

The majority of wild mammal host species of EIDs in this study are within the IUCN category Least Concern ( $n=37,90.2 \%)$. One species is listed as Near Threatened (large flying fox) and three as Vulnerable (southern pigtailed macaque, Lyle's flying fox and grey-headed flying fox). Population trend is unknown for 10 of the identified wild mammal EID host species. Only one species (bandicoot rat), has a population classed as increasing: the remainder are stable $(n=18)$ or decreasing $(n=12)$ (IUCN 2010).

Habitat data provided by the IUCN Red List identify five species of wild mammal EID hosts which are not recorded as using HME. The remainder of species (36, or $88 \%)$ use plantations $(n=25)$, rural gardens $(n=18)$, pastureland $(n=18)$, arable land $(n=17)$, urban $(n=14)$, degraded forest (14) or mines, tunnels and artificial roosting caves $(n=2)$ in addition to their natural habitat(s). This does not include any measure of frequency of HME use, but indicates the adaptive nature of these species. Only two species are considered to be nearly exclusively synanthropic, the brown rat and the Asian house shrew. The proportion of total wild mammals in the study area using HME is $33 \%$ (616 species).

For the 41 EID host species under consideration, 16 $(39.0 \%)$ are described as under conservation threat of targeted hunting pressure within their habitat range (IUCN 2010). We report an increased risk of EID transmission associated with conservation threat from hunting $(\mathrm{OR}=2.1 ; P<0.05)$. Species under hunting pressure include the four species that are classified Near Threatened or Vulnerable. The five species of EID hosts not known from HME were also not recorded as under threat from hunting.

\section{Discussion}

We demonstrate that wild mammals are the largest group of wildlife hosts of zoonotic EIDs in Australasia, South East 
Table 1. Stratum-specific and Summary Odds Ratios: HME use and EID host status stratified by taxonomic order and conservation status

\begin{tabular}{|c|c|c|c|c|c|}
\hline Taxonomic order & OR & $95 \% \mathrm{CI}$ & Conservation status & OR & $95 \% \mathrm{CI}$ \\
\hline Rodents & 15.40 & $4.42,53.48$ & Least concern & 8.75 & $3.39,22.61$ \\
\hline Bats & 7.67 & $1.7,34.7$ & & & \\
\hline Primates & 10.78 & $0.54,215.81$ & Higher risk categories & 32.9 & $1.77,614.9$ \\
\hline Eulipotphyla & 19.0 & $0.89,407.37$ & & & \\
\hline Carnivore & 11.60 & $0.58,231.37$ & Summary $\mathrm{OR}_{\mathrm{MH}}$ & 10.26 & $4.15,33.05$ \\
\hline Summary $\mathrm{OR}_{\mathrm{MH}}$ & 14.49 & $5.71,45.74$ & & & \\
\hline
\end{tabular}

Asia and East Asia and that this group is dominated by synanthropic wild mammals $\left(\mathrm{OR}_{\mathrm{MH}}=14.49 ; 95 \% \mathrm{CI}\right.$ $5.71,45.74)$. This pattern remains regardless of a species conservation status or taxonomic order. This suggests that it is the synanthropic species from any taxa that are most likely to be EID hosts.

However, this does not imply that the microbial fauna of synanthropic wild mammals is more pathogenic than animals that are not synanthropic (or of higher risk conservation status). Rather, we interpret this as a reflection of exposure opportunity, which accords with the findings of previous studies (Cleaveland et al. 2001; Taylor et al. 2001; Woolhouse 2002; Woolhouse and Gaunt 2007). Intrinsic characteristics of the pathogens themselves, the modes of transmission required and the behaviours that affect these, limit successful transmission of pathogens from wildlife in proximity with humans and domestic animals (e.g. Childs et al. 2007; Pulliam 2008). The small proportion of total wildlife, and of total synanthropic wild mammals, that are currently the source of emerging infectious diseases in the study region may reflect these limits.

Our use of the term 'synanthropy' is necessarily broad. In this study, given the constraints of available data, the use of human-modified habitats by wildlife includes all levels of feeding, shelter and social activity in these environments. Terms such as 'full-', 'casual-' and 'tangential-' have been used elsewhere for avian synanthropes (Johnston 2001). Gradients of synanthropy of insect vectors and rodents have been examined in disease studies within particular settings (Elshazly et al. 2008; Forattini et al. 2000; Figueroa-RoaI and LinharesII 2004; Montoya et al. 2009; Nuorteva 1963). We found it inappropriate to devise categories of synanthropy for a multi-region, multi-taxa study, and hence we present our results as a general finding. As described in the result section, host species may use multiple categories of human environments. Synanthropy is not an absolute, or fixed, state; it declines as fewer resources are provided by humans or by the landscapes they have modified (Shochat et al. 2006; Marzluff et al. 2008). In our final analysis, we combined all categories of HME into a broad but robust term.

Wild mammal hosts of EIDs are more frequently found to be species of low risk conservation status. Whilst this status is not necessarily synonymous with a species being numerous or frequently encountered, it includes many such species. Within data limitations, our analyses suggest that being of Least Concern conservation status is positively correlated with HME use. Meanwhile, the relationship with synanthropy remains strong at all levels of stratified variables (taxa and conservation status), indicating that any potential confounding or effect modification is of limited importance effecting this analysis.

The data used in this study did not allow extended examination of all opportunities for human exposure through hunting (e.g. consumption and persecution of abundant, pest species). We do report a positive association where hunting is recorded as a conservation threat for EID hosts. This overlaps the hosts for which synanthropy, and conservation risk, are also determinants. Hence, it does not appear here to be a mode of transmission from more elusive, non-synanthropic animals but may represent the mechanism for a proportion of the transmission from synanthropes in this region. Hunting is a serious and escalating threat to many species of wild mammals in both high and lower risk conservation categories, particularly in South East Asia (IUCN 2010). The relative importance of synanthropy, hunting, conservation status and EID risk is a topic for further research. Building more complex models with these data is limited by the small number of EID hosts in some strata of this analysis (particularly where the risk factor of interest is absent).

In this study, five EID host species were listed as neither hunted or as using HMEs, suggesting further modes of 
transmission. These species may be important in the maintenance of the pathogen, including transmission to synanthropic (or hunted) species. This appears to be the case with regard to the yellow-bellied sheath-tailed bat and Australian bat lyssavirus where most human exposure occurs through transmission from synanthropic fruit bats (Field 2005; McCall et al. 2000), and may be so for the lesser horseshoe bat and SARS coronavirus (Janies et al. 2008; Lau et al. 2010; Tu et al. 2004). Two of three species of rodent in this category are listed as periodic agricultural pests (Afonin et al. 2008) following disruption of their natural habitat. For example, reed vole populations in China surged after the construction of the Three Gorges Dam combined with the over-hunting of reptile predators (Wang et al. 2009; Yan et al. 2010).

An assessment of change in synanthropic attributes over time was not possible in this study and so we cannot explain the documented rise in zoonotic EIDs from wildlife (Jones et al. 2008). However, like other regions of high (mammal) biodiversity, South East Asia, East Asia and Australasia have accelerated land transformation and biodiversity loss. Many species are under strong selection pressure to accommodate human environments. We consider that this is why our findings concur with evidence that high mammal diversity is a predictor of zoonotic EIDs (Jones et al. 2008). Simplified human ecosystems that replace natural systems are typically characterised by reduced diversity of animal species with increased number of individual animals (Bradley and Altizer 2007; Meade and Earickson 2000). This may facilitate pathogen amplification and host switching in addition to the physical opportunities for human and livestock exposure (Keesing et al. 2010).

The results of this study, while robust, should be interpreted cautiously. The study region represents a broad spectrum of different surveillance capabilities across time, space and cultures. Although we did not try to correct for reporting bias, as our interest is in the identification and characteristics of hosts, we believe that our study has face validity. That is, similar numbers of EIDs are found in other reports, some spanning longer periods or global in extent (e.g. over 55 EIDs were identified by IOM as threats to the United States in 1992 (IOM 1992); 145 zoonotic wildlife EIDs were identifies globally 1940-2008 (Jones et al. 2008), 87 new human diseases identified since 1980 (Woolhouse and Gaunt 2007).

Furthermore, we found similar proportions of EIDs to be zoonotic and in wildlife hosts (67\% zoonotic, $63 \%$ of these from wildlife) as in other studies analysing global data (e.g. 60.3, $71.8 \%$, respectively (Jones et al. 2008)). Elsewhere $75 \%$ of EIDs are found to be zoonoses (Taylor et al. 2001). In an earlier global study of novel diseases since 1980, the majority of zoonotic hosts (domestic and wildlife) reported were also mammals, particularly artiodactyls, carnivores and rodents; but also bats, primates, birds and marsupials, respectively (Woolhouse and Gaunt 2007). These results are shown as an overlay on Fig. 1. This approximates the results of our study, although the dramatically greater contribution of rodents is a consequence of our inclusion of re-emerging diseases. As discussed earlier, marsupials are excluded, contributing to the marginally significantly different distribution of EID hosts across orders compared to the total mammalian fauna of the study area. The conspicuous lack of EID hosts from the species-rich marsupial order Diprotodonts in Fig. 2 is also a result of this exclusion.

We have considered and examined the several ways in which relationship bias might have entered this dataset and hence analysis, as a consequence of various literature-searching, field-sampling and inclusion/exclusion criteria. We judge, however, that there is no likely significant bias of this kind. A few points require further comment.

We have examined a larger group of hosts by the inclusion of hosts of re-emerging diseases, than if only novel (predominantly bat) hosts were included. This strengthens the association with synanthropy. However, our hypothesis is also supported by the predominance of synanthropic hosts for the novel bat diseases (Table 1). We have accepted different sampling and diagnostic methods used to identify hosts within the literature: detailed phylogenic analysis was rarely available. Some hosts of reemerging diseases may not be the original source of the pathogen, and may be hosts to multiple (adapted) diseases (e.g. Easterbrook et al. 2007). We include these in the list of EID hosts (Table 2) where the ecology of a disease in some part of the study region depends on such a species for emergence or re-emergence.

Studies to identify the wildlife hosts of zoonotic EIDs may be biased by opportunistic wildlife sampling, therefore favouring common and synanthropic species. However, the literature reviewed in this study provides ample evidence of extensive searches for wild or domestic hosts, including zoological collections, wildlife markets and extensive field sampling (e.g. Cheng et al. 2007; Johansen et al. 2005; Kariwa et al. 2007; Vanittanakom et al. 2006; Webster 2004, etc.). None of the reported sampling strategies have been 


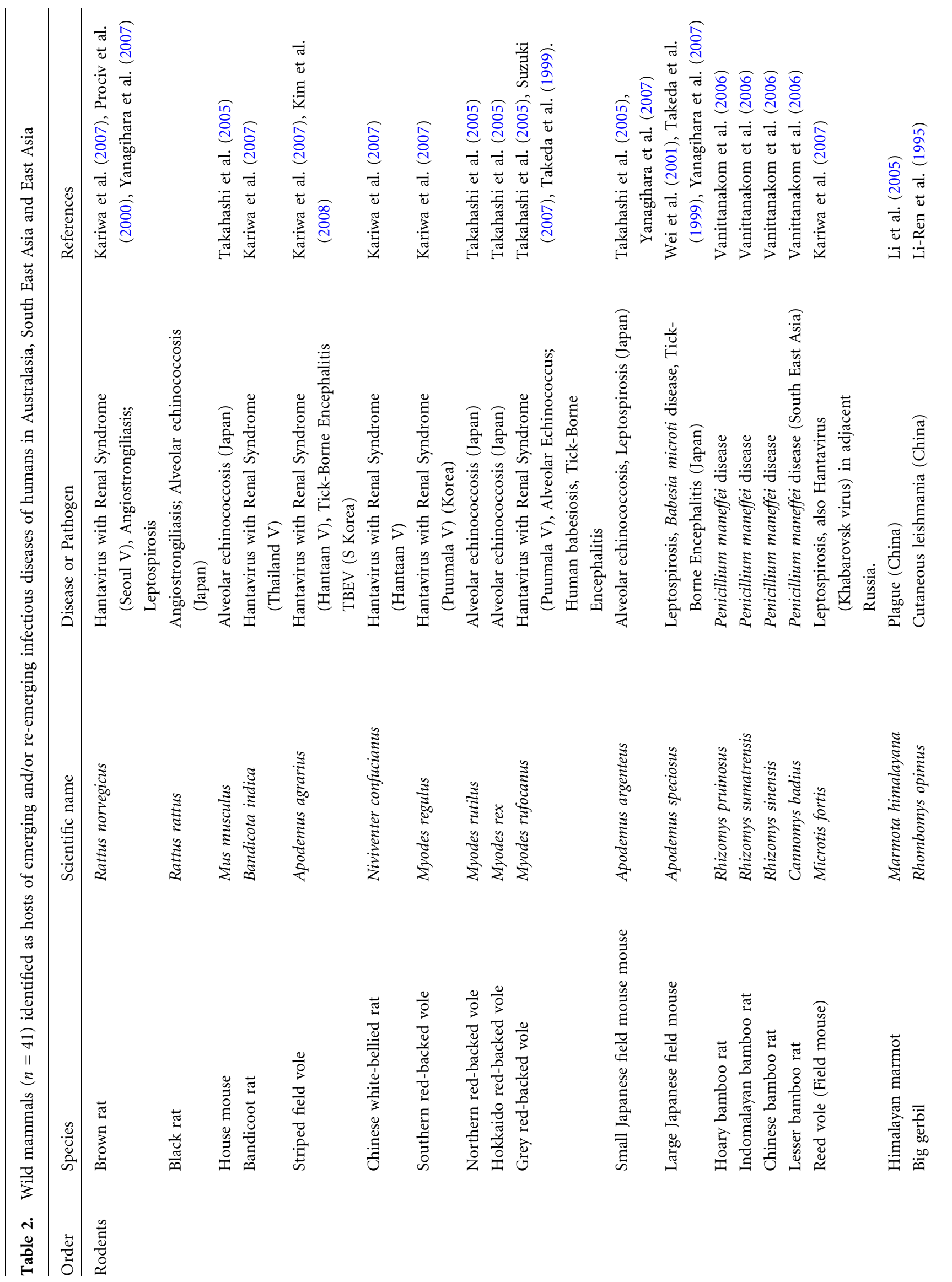




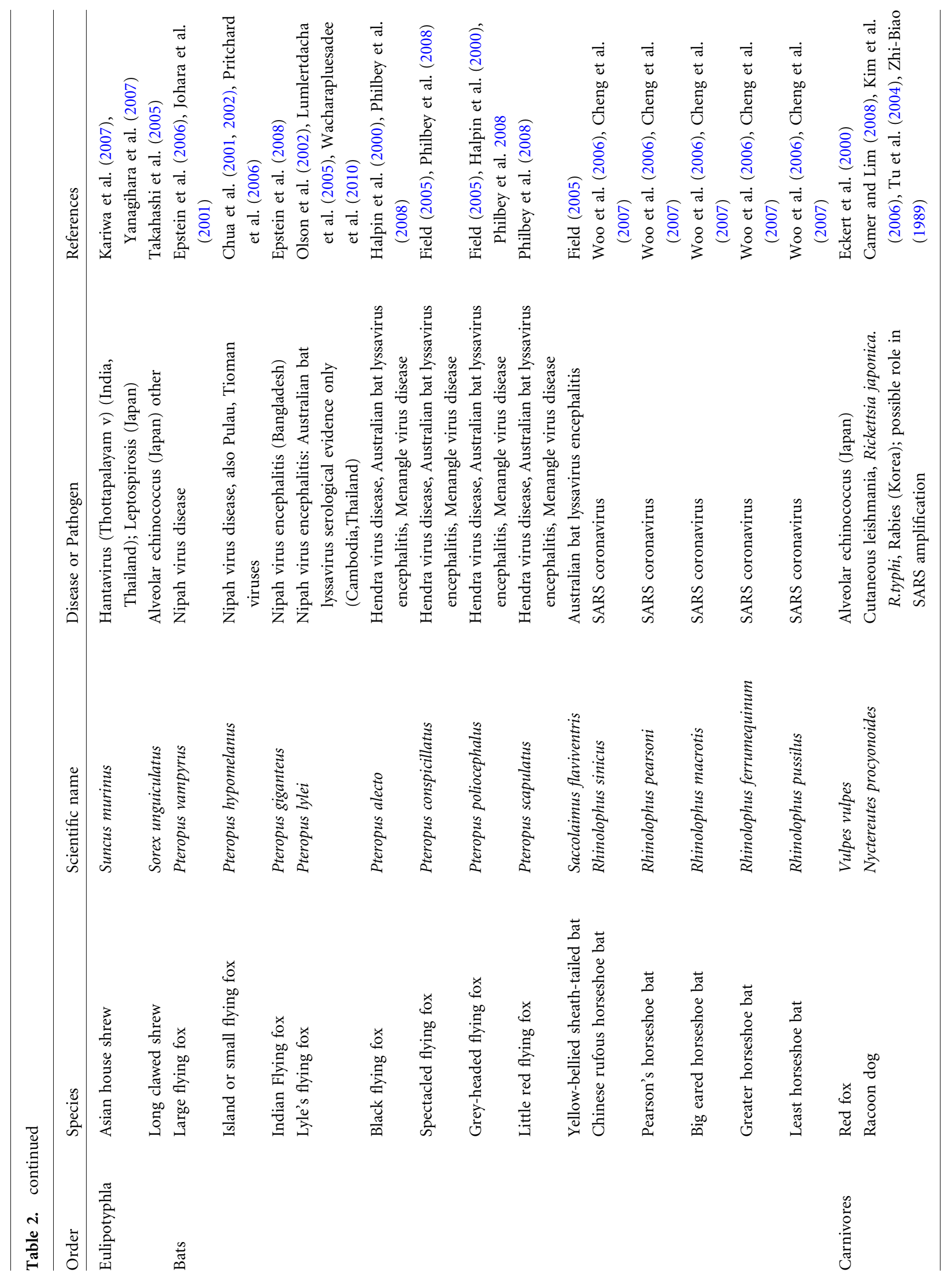




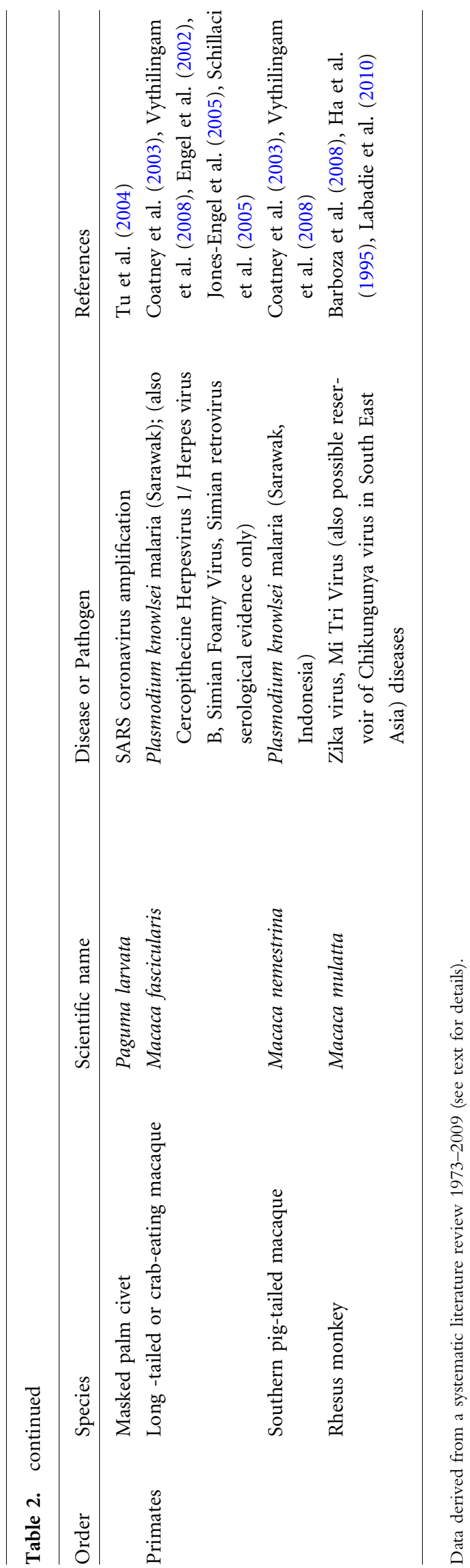

explicitly based on an assumption of synanthropy as defined in this study.

Our central hypothesis that synanthropy is a dominant characteristic of wild mammal EID hosts should be examined in other geographic regions. Future research should also focus down at disease and location levels, in order to understand the temporal and interspecies relationships within the landscape. We suggest that our broad approach can be used as a template for further integrated research.

Expanding HMEs and hunting are not only potential drivers of EIDs from wildlife, they are also major causes of biodiversity loss of wild mammals (IUCN 2010). The links between the latter and the rise of zoonotic EIDs from wildlife should be further explored as interdisciplinary research capacity gathers momentum (e.g. Sala et al. 2009; TEEB 2010). Our finding of a negative consequence of ecological disruption supports the evidence that intact ecosystems have a disease-regulating role (MEA 2005).

\section{CONCLUSION}

Australasia, South East Asia, East Asia are three diverse regions that are the focus of much attention in the global rise of EIDs. We have confirmed the results from previous studies that the majority of EIDs are zoonotic and that EIDs of wildlife origin, predominantly from mammals, are the majority of these. We have demonstrated strong associations with synanthropy by analysing the attributes of wild mammal hosts of EIDs, the latter identified through a systematic literature review. Attributes of wild mammals were extracted from IUCN biodiversity data. We also demonstrate associations with low risk conservation status and threat from hunting. We hypothesise that human-induced landscape change inadvertently selects for synanthropic wild mammals and increases our exposure to their pathogens. This suggests a mechanism by which accelerating habitat and biodiversity loss is driving the rise of this group of EIDs. The suite of synanthropic species may change as our human environments change. This is likely to be a determinant of future EIDs of wildlife origin.

\section{REFERENCES}

Afonin A, Greene S, Dzyubenko N, Frolov A (2008). Interactive Agricultural Ecological Atlas of Russia and Neighboring Countries. Economic Plants and their Diseases, Pests and Weeds. http://www.agroatlas.ru. Accessed 1 Nov 2010. 
Barboza P, Tarantola A, Lassel L, Mollet T, Quatresous I, Paquet C (2008) Emerging viral infections in South East Asia and the Pacific region. Medecine et Maladies Infectieuses 38:5134-5523

Bradley C, Altizer S (2007) Urbanization and the ecology of wildlife diseases. Trends in Ecology \& Evolution 22:95-102

Camer GA, Lim CW (2008) Detection of spotted fever and typhus group rickettsial infection in wild raccoon dogs (Nyctereutes procyonoides koreensis) in Chonbuk province, Korea. Journal of Zoo and Wildlife Medicine 39:145-147

CDC (2008) Epi Info 5.3.1. Centers for Disease Control and Prevention. 1600 Clifton Rd. Atlanta, GA 30333, USA.

Cheng VC, Lau SK, Woo PC, Yuen K (2007) Severe acute respiratory syndrome coronavirus as an agent of emerging and reemerging infection. Clinical Microbiology Reviews 20:660-694

Childs J, Mackenzie J, Richt J (2007) Wildlife and Emerging Disease: The Biology, Circumstances and Consequences of Cross Species Transmission, Berlin: Springer

Chomel BB, Belotto A, Meslin FX (2007) Wildlife, exotic pets, and emerging zoonoses. Emerging Infectious Diseases 13:6-11

Chua K, Koh CL, Hooi PS, Wee KF, Khong JH, Chua BH, et al. (2002) Isolation of Nipah virus from Malaysian Island flyingfoxes. Microbes and Infections 4:145-151

Chua K, Wang LF, Lam SK, Crameri G, Yu M, Wise T, et al. (2001) Tioman virus, a novel paramyxovirus isolated from fruit bats in Malaysia. Virology 283:215-229

Cleaveland S, Laurenson MK, Taylor L (2001) Diseases of humans and their domestic mammals: pathogen characteristics, host range and risk of emergence. Philosophical Transactions of the Royal Society of London B 356:991-999

Coatney G, Collins WE, Warren M, Contacos P (2003) The primate malarias [CD-ROM; original book published 1971]. Atlanta: Centers for Disease Control and Prevention.

Cox D, Snell E (1989) Analysis of Binary Data, 2nd ed., London: Chapman and Hall

Daszak P, Cunningham A, Hyatt A (2000) Emerging infectious diseases of wildlife: threats to biodiversity and human health. Science 287:443-449

Dobson A, Cattadori I, Holt R, Ostfeld R, Keesing F, Krichbaum K, et al. (2006) Sacred cows and sympathetic squirrels: the importance of biological diversity to human health. Human Health PLoS-Medicine 3:e231. doi:10.1371/journal.pmed.0030231

Easterbrook JD, Kaplan JB, Vanasco NB, Reeves WK, Purcell RH, Kosoy MY, et al. (2007) A survey of zoonotic pathogens carried by Norway rats in Baltimore, Maryland, USA. Epidemiology and Infection. 135:1192-1199

Eckert J, Conraths FJ, and Tackmann K (2000). Echinococcosis: an emerging or re-emerging zoonosis? International Journal for Parasitology. 30:1283-1294.

Elshazly A, Awad SI, Azab MS, Elsheikha HM, Abdel-Gawad AG, Khalil HH, et al. (2008) Helminthes of synanthropic rodents (Rodentia: Muridae) from Dakahlia and Menoufia, Egypt. $J$ Egypt Soc Parasitol 38:727-740

Engel G, Jones-Engel L, Schillaci MA, Suaryana KG, Putra A, Fuentes A, et al. (2002) Human exposure to herpesvirus B-seropositive macaques, Bali, Indonesia. Emerging Infectious Diseases 8:789-795

Epstein JH, Field HE, Luby S, Pulliam J, Daszak P (2006) Nipah virus: impact, origins, and causes of emergence. Current Infectious Disease Reports 8:59-65

Epstein J, Prakash V, Smith CS, Daszak P, McLaughlin AB, Meehan G, et al. (2008) Henipavirus infection in fruit bats
(Pteropus giganteus), India. Emerging Infectious Diseases 14:1309-1311

Epstein PR (2002) Biodiversity, climate change and emerging infectious diseases. In: Conservation Medicine Ecological Health in Practice, Aguirre A, Ostfeld R, Tabor G, House C, Pearl M (editors), Oxford: Oxford University Press

Field H (2005). Ecology of Hendra virus and Australian Bat Lyssavirus. Thesis. University of Queensland, Brisbane.

Figueroa-RoaI L, Linhares AX II (2004) Synanthropy of Muscidae (Diptera) in the city of Valdivia, Chile. Neotropic Entomology 33:647-651

Forattini OP, Kakitani I, Corte La, dos Santos R, Kobayashi KM, Ueno HM, Fernández Z (2000) The synanthropic potential of Kerteszia and Culex mosquitoes (Diptera: Culicidae) in Southeastern Brazil. Revista Saúde Pública/Journal of Public Health 34:565-569

Froment A (2009) Biodiversity and health: the place of parasitic and infectious disease. In: Biodiversity Change and Human Health, Sala O, Meyerson L, Parmesan C (editors), Washington: Island Press, pp 211-227

Ha DQ, Calisher CH, Tien PH, Karabatsos N, Gubler D (1995) Isolation of a newly recognized alphavirus from mosquitoes in Vietnam and evidence for human infection and disease. American Journal of Tropical Medicine and Hygeine 53:100-104

Halpin K, Young PL, Field HE, Mackenzie J (2000) Isolation of Hendra virus from pteropid bats: a natural reservoir of Hendra virus. Journal of General Virology 81:1927-1932

Harley D, Sleigh A, Ritchie S (2001) Ross river virus transmission, infection and disease: a cross-disciplinary review. Clinical Microbiology and Infection 14:909-932

IOM (1992) Emerging infections: microbial threats to health in the United States. National Academies Press, Washington, DC.

IOM (2003) Microbial threats to health: emergence, detection and response, Washington: National Academies Press

IUCN (2010). IUCN Red List of Threatened Species. Version 2010.4. http://www.iucnredlist.org. Accessed Jan-March 2010.

Janies D, Habib F, Alexandrova B, Hilld A, Pol D (2008) Evolution of genomes, host shifts and the geographic spread of SARS$\mathrm{CoV}$ and related coronaviruses. Cladistics 23:1-20

Johansen C, Mackenzie JS, Smith DW, Lindsay M (2005) Prevalence of neutralising antibodies to Barmah Forrest, Sindbis and Trubanaman viruses in animals and humans in the south-west of Western Australia. Australian Journal of Zoology 53:51-58

Johara MY, Field H, Rashdi AM, Morrissy CJ, van der Heide B, Rota P, et al. (2001) Nipah virus infection in bats (Order Chiroptera) in peninsular Malaysia. Emerging Infectious Diseases 7:439-441

Johnston JF (2001) Synanthropic birds of North America. In: Avian Ecology and Conservation in an Urbanising World, Mazluff J, Bowman R, Donnelly R (editors), Norwell, USA: Kluwer Academic Publishers

Jones-Engel L, Engel G, Schillaci M, Rompis A, Putra A, Suaryana KG, et al. (2005) Primate-to-human retroviral transmission in Asia. Emerging Infectious Diseases 11:1028-1035

Jones KE, Patel NG, Levy MA, Storeygard A, Balk D, Gittleman JL, et al. (2008) Global trends in emerging infectious diseases. Nature 451:U990-U994

Kariwa H, Yoshimatsu K, Arikawa J (2007) Hantavirus infection in East Asia. (Special issue: Recent research progress on emerging infectious diseases in Asia and Oceania.). Comparative Immunology, Microbiology \& Infectious Diseases 30:341-356 
Keesing F, Belden L, Daszak P, Dobson A, Drew Harvell C, Holt R, et al. (2010) Impacts of biodiversity on the emergence and transmission of infectious diseases. Nature 468:647-652

Kim CH, Lee CG, Yoon HC, Nam HM, Park CK, Lee JC, et al. (2006) Rabies, an emerging disease in Korea. Journal of Veterinary Medicine. Blackwell Publishing, Berlin, pp 111-115.

Kim S-Y, Yun S-M, Han MG, Lee IW, Lee NY, Jeong Y, et al. (2008) Isolation of tick-borne encephalitis viruses from wild rodents, South Korea. Vector-Borne and Zoonotic Diseases 8:7-14

Kruse H, Kirkemo A, Handeland K (2004) Wildlife as source of zoonotic infections. Emerging Infectious Diseases 10:67-72

Labadie K, Larcher T, Joubert C, Mannioui A, Delache B, Brochard P, et al. (2010). Chikungunya disease in nonhuman primates involves long-term viral persistence in macrophages. The Journal of Clinical Investigation. 120:894-906.

Lau S, Li K, Huang Y, Shek C, Tse H, Wang M, et al. (2010) Ecoepidemiology and complete genome comparison of different strains of severe acute respiratory syndrome-related rhinolophus bat coronavirus in china reveal bats as a reservoir for acute, self-limiting infection that allows recombination events. Journal of Virology 84:2808-2819

Li-Ren G, Yuan-Qing Y, Jing-Qi Q, Wei-Xia S (1995) Discovery and study of Leishmania turanica for the first time in China. WHO Bulletin OMS 73:667-672

Li M, Song Y, Li B, Wang Z, Yang R, Jiang L, et al. (2005) Asymptomatic Yersinia pestis infection, China (letter). Emerging Infectious Diseases 11:1494-1496

Lumlertdacha B, Boongird K, Wanghongsa S, Wacharapluesadee S, Chanhome L, Khawplod P, et al. (2005) Survey for bat lyssaviruses, Thailand. Emerging Infectious Diseases 11:232-236

Marzluff J, Sculenberger E, Endlicher W, Alberti M, Bradley G, Ryan C, et al. (2008) Urban Ecology: An International Perspective on The Interactions Between Humans and Nature, New York: Springer

MEA (2005) Ecosystems and Human Well-Being: Biodiversity Synthesis, Washington, D.C.: World Resources Institute

Meade MS, Earickson R (2000) Developmental change and human health. In: Medical Geography. New York: The Guildford Press, pp 107-150.

McCall B, Epstein JH, Neill AS, Heel K, Field H, Barrett J, et al. (2000) Potential human exposure to Australian bat lyssavirus, Queensland, 1996-1999. Emerging Infectious Diseases 6:259-264

Montoya L, Augusto G, Sanchez R, David J, Marta WE (2009) Synanthropy of Calliphoridae (Diptera) from La Pintada Antioquia-Colombia. Review of Colombian Entomology 35:73-82

Morse S (1995) Factors in the emergence of infectious diseases. Emerging Infectious Diseases 1:7-15

Motulsky H (2002) Graphpad Quick Calcs Software. GraphPad Software, 2236 Avenida de la Playa, La Jolla, CA 92037, USA www.graphpad.com.

Nuorteva P (1963) Synanthropy of blowflies (Diptera, Calliphoridae) in Finland. Ann. Entomol. Fenn. 29:1-49

Olson J, Rupprecht C, Rollin PE, An US, Niezgoda M, Clemins T, et al. (2002) Antibodies to nipah-like virus in bats (Pteropus lylei), Cambodia. Emerging Infectious Diseases 8:987-988

Ostfeld R, Keesing F (2000) Biodiversity and disease risk: the case of Lyme disease. Conservation Biology 14:722-728

Philbey AW, Kirkland PD, Ross AD, Field HE, Srivastava M, Davis RJ, et al. (2008). Infection with Menangle virus in flying foxes (Pteropus spp.) in Australia. Australian Veterinary Journal 86:449-454
Pongsiri M, Roman J, Ezenwa VO, Goldberg TL, Koren HS, Newbold SC, et al. (2009) Biodiversity loss affects global disease ecology. BioScience 59:945-954

Pritchard L, Chua KB, Cummins D, Hyatt A, Crameri G, Eaton BT, et al. (2006) Pulau virus; a new member of the Nelson Bay orthoreovirus species isolated from fruit bats in Malaysia. Archives of Virology 151:229-239

Prociv P, Spratt DM, Carlisle MS (2000) Neuro-angiostrongylus: unresolved issues. International Journal of Parasitology 30:12951303

Pulliam J (2008) Viral host jumps: moving towards a predictive framework. Ecohealth 5:80-91

Reperant LA (2010) Applying the theory of island biogeography to emerging pathogens: toward predicting the sources of future emerging zoonotic and vector-borne diseases. Vector-Borne and Zoonotic Diseases 10:105-110

Sala OIn: Meyerson LAParmesan C (editors) (2009) Biodiversity Change and Human Health: From Ecosystem Services to Spread of Disease, Washington: Island Press

Schillaci MA, Jones-Engel L, Engel GA, Paramastri Y, Iskandar E, Wilson B, et al. (2005) Prevalence of enzootic simian viruses among urban performance monkeys in Indonesia. Tropical Medicine and International Health 10:1305-1314

Sergeant E (2009). Epitools epidemiological calculators. AusVet Animal Health Services and Australian Biosecurity Cooperative Research Centre for Emerging Infectious Disease. http://epitools. ausvet.com.au.

Shochat E, Warren PS, Faeth SH, McIntyre NE, Hope D (2006) From patterns to emerging processes in mechanistic urban ecology. Trends in Ecology \& Evolution 21:186-191

Suzuki Y (2007) Multiple transmissions of tick-borne encephalitis virus between Japan and Russia. Genes and Genetic Systems 82:187-195

Swift L, Hunter PR, Lees AC, Bell DJ (2007) Wildlife trade and the emergence of infectious diseases. Ecohealth 4:25-30

Takahashi K, Uraguchi K, Kudo S (2005) The epidemiological status of Echinococcus multilocularis in animals in Hokkaido, Japan. Mammal Study 30:S101-S105

Takeda T, Ito T, Osada M, Takahashi K, Takashima I (1999) Isolation of tick-borne encephalitis virus from wild rodents and a seroepizootiologic survey in Hokkaido, Japan. American Journal of Tropical Medicine and Hygiene 287-291:287-291

Taylor L, Latham S, Woolhouse M (2001) Risk factors for human disease emergence. Philosophical Transaction of the Royal Society London Series B 356:983-989

TEEB (2010) The economics of ecosystems and biodiversity: mainstreaming the economics of nature: a synthesis of the approach, conclusions and recommendations of TEEB. www. teebweb.org.

Tu C, Crameri G, Kong X, Chen J, Sun Y, Yu M, et al. (2004) Antibodies to SARS coronavirus in civets. Emerging Infectious Diseases 10:2244-2248

Vanittanakom N, Cooper C Jr, Fisher M, Sirisanthana T (2006) Penicillium marneffei infection and recent advances in the epidemiology and molecular biology aspects. Clinical Microbiology Reviews 19:95-110

Vythilingam N, NoorAzian C, Huat M, Jiram T, Yusri T, Azahari T, et al. (2008) Plasmodium knowlesi in humans, macaques and mosquitoes in peninsular Malaysia. Parasite \& Vectors 1:26. doi:10.1186/1756-3305-1-26 
Wacharapluesadee S, Boongird K, Wanghongsa S, Ratanasetyuth N, Supavonwong P, Saengsen D, et al. (2010) A longitudinal study of the prevalence of Nipah virus in Pteropus lylei bats in Thailand: evidence for seasonal preference in disease transmission. Vector Borne Zoonotic Disease 10:183-190

Wang J, Huang J, Wu J, Han X, Lin G (2009) Ecological consequences of the three gorges dam: insularising affects foraging behaviour and dynamics of rodent populations. Frontiers in Ecology and the Environment 7:13-19

Webster RG (2004) Wet markets-a continuing source of severe acute respiratory syndrome and influenza? Lancet (British edition) 363:234-236

Wei Q, Tsuji M, Zamoto A, Kohsaki M, Matsui T, Shiota T, et al. (2001) Human babesiosis in Japan: isolation of babesia microtilike parasites from an asymptomatic transfusion donor and from a rodent from an area where babesiosis is endemic. Journal of Clinical Microbiology 39:2178-2183

WHO, FAO, OIE (2004) Report of the WHO/FAO/OIE joint consultation on emerging zoonotic diseases, 3-5 May 2004. Geneva, Switzerland.

Wolfe ND, Daszak P, Kilpatrick AM, Burke DS (2005) Bush meat hunting, deforestation and prediction of zoonotic disease. Emerging Infectious Diseases 11:1822-1827
Woo PC, Lau SK, Yuen K (2006) Infectious diseases emerging from Chinese wet-markets: zoonotic origins of severe respiratory viral infections. Current Opinion in Infectious Diseases 19:401-407

Woolhouse M, Gaunt E (2007) Ecological origins of novel human pathogens. Critical Reviews in Microbiology 33:231-242

Woolhouse MEJ (2002) Population biology of emerging and reemerging pathogens. Trends in Microbiology 10:3-7

Yanagihara Y, Villanueva SY, Yoshida S, Okamoto Y, Masuzawa T (2007) Current status of leptospirosis in Japan and Philippines. (Special issue: Recent research progress on emerging infectious diseases in Asia and Oceania.). Comparative Immunology, Microbiology \& Infectious Diseases 30:399-413

Yan L, Ren Y-H, Zhang J, Li P-L, Wang X-L, Mao D-Q, et al. (2010) Relationship between the incidence of HFRS and changes of land-use in big three gorges area of Chongqing municipality, China. Frontiers of Medicine in China 4:199-203

Zhi-Biao X (1989) Present situation of visceral leishmaniasis in China. Parasitol Today 5:224-228 